\title{
Perivascular adipose tissue from the internal mammary artery in patients with severe coronary artery atherosclerosis
}

\author{
Adam Kowalówka1', Grzegorz Machnik², Marek Deja1', Bogusław Okopień², Zbigniew Gąsior³, Maciej Haberka³ \\ 1 Department of Cardiac Surgery, Medical University of Silesia, Katowice, Poland \\ 2 Department of Internal Medicine and Clinical Pharmacology, Medical University of Silesia, Katowice, Poland \\ 3 Department of Cardiology, Medical University of Silesia, Katowice, Poland
}

\section{KEY WORDS}

adipose tissue, coronary artery disease, internal mammary artery

\section{EDITORIAL}

by Mikołajczyk

and Guzik, see p. 1194

\begin{abstract}
BACKGROUND The internal mammary artery (IMA) is routinely used as an arterial graft for coronary artery bypass grafting with an excellent long-term patency rate, but its protective mechanism is unclear. AIMS We evaluated the differences between the expression of several gene in perivascular adipose tissue from the IMA (PVAT-IMA) as compared with other fat depots in patients with severe coronary artery disease. METHODS A total of 53 patients (13 women) with severe coronary artery disease and preserved left ventricular ejection fraction were scheduled for coronary artery bypass grafting. Clinical assessment, anthropometric parameters, and quantification of fat depots were performed in all patients. The relative expression of the following genes were obtained in PVAT-IMA, as well as epicardial, pericardial, and subcutaneous (SF) fat samples: angiotensinogen (AGT), angiotensin I converting enzyme 1 and 2 (ACE1 and $A C E 2$ ), glucagon-like peptide receptors type 1 and 2 (GLP1R and GLP2R), phospholipid transfer protein (PLTP), adiponectin (ADIPOQ), omentin-1 (ITLN1), and uncoupling protein 1 (UCP1).

RESULTS The expression of UCP1 (median [interquartile range [IQR], $2.5[0.91-16.6] ; P<0.01$ ) and $A G T$ (2.22 [0.65-6.2]; $P<0.01$ ) was higher in PVAT-IMA compared with the SF depot. ADIPOQ expression was higher in pericardial and epicardial fat depots as compared with PVAT-IMA. The expression of ITLN1 was increased in PVAT-IMA as compared with epicardial and pericardial fat $(P<0.001)$.

CONCLUSIONS PVAT-IMA revealed differences in the expression of selected genes in relation to SF. We found a higher expression of ITLN1 in PVAT-IMA compared with other adipose tissue depots, which could be associated with protective mechanisms against atherosclerosis in IMA. However, this remains a subject for further studies.
\end{abstract}

INTRODUCTION Obesity is an important risk factor for coronary artery disease and atherosclerosis. ${ }^{1,2}$ Both diseases result from inflammatory responses among various genetic and nongenetic factors. ${ }^{3}$ However, perivascular adipose tissue (PVAT) releases adipokines and other vasoactive factors. ${ }^{4,5}$ Visceral and epicardial adiposity revealed closer association with cardiovascular risk compared with subcutaneous fat, 6,7 possibly due to stronger immune cell infiltration and higher expression of proinflammatory cytokines in this adipose tissue depot. ${ }^{8}$ Although recent papers have suggested an important role of PVAT in arterial atherosclerosis, the internal mammary artery (IMA) is an exception and shows nearly no atherosclerosis. ${ }^{9}$ Recently, PVAT from the IMA (PVAT-IMA) has been evidenced to have vasodilatory effect. ${ }^{10}$ It is a primary arterial graft used for coronary artery bypass grafting $(C A B G)$ with the best 10-year life-patency. ${ }^{11,12}$ Overweight patients were found to have partially reduced endothelial function in the IMA. ${ }^{13}$ The evidence supporting the potential explanations and properties of PVAT-IMA depot is still 


\section{WHAT'S NEW?}

We report a specific analysis study of different genes in adipose tissue derived from the perivascular mammary artery and epicardial, pericardial, or subcutaneous fat. The most prominent differences were found between adipose tissue from the perivascular internal mammary artery and the epicardium, particularly, a higher expression of omentin-1 (ITLN1) in fat from the internal mammary artery. We consider it as one of the possible explanations of the protective properties of the internal mammary artery grafts against atherosclerosis.
Poland) in a reaction volume of $20 \mu \mathrm{l}$, RNA was reverse transcribed and the reaction mixture was diluted in a ratio of 1 to 4 with nuclease-free water. Real-time quantitative polymerase chain reaction (QPCR) was performed in 2 steps. The glyceraldehyde 3-phosphate dehydrogenase (GAPDH) gene was used as a reference gene. For QPCR template, $2 \mu \mathrm{l}$ of the reverse transcription reaction mixture was used. Real-time QPCR was performed using the SYBR Select Master Mix (Thermo Fisher Scientific, Warsaw, Poland) in a total volume of 20 $\mu l$ that contained $200 \mathrm{nM}$ of each (forward and reverse) gene-specific primers. All QPCR primers were delivered from the PrimerBank database (https://pga.mgh.harvard.edu/primerbank). ${ }^{16}$ The probability of false-positive results from genomic DNA was ruled out because primer pairs spanned the intron/ exon boundary. All reactions were performed using the Roche Light $\mathrm{Cy}^{-}$ cler 480 Instrument II (Roche Diagnostics, Warsaw, Poland) with a standardized thermal profile protocol.

The increase in fluorescence was measured in real time and threshold cycle values $(\mathrm{Ct})$ were received. The target gene $\mathrm{Ct}$ number was normalized to the endogenous reference human GAPDH. Then, gene expression relative to SF was evaluated with the formula $2^{(-\Delta \Delta \mathrm{Ct})} \cdot{ }^{17}$ The relative expressions of the following genes were assessed: angiotensinogen $(A G T)$, angiotensin I converting enzyme 1 and 2 ( $A C E 1$ and $A C E 2$ ), receptors for glucagon-like peptide 1 and 2 (GLP1R and GL$P 2 R$ ), phospholipid transfer protein (PLTP), adiponectin (ADIPOQ), omentin-1 (ITLN1), and uncoupling protein-1 (UCP1).

Statistical analysis Results are shown as means (SD) for normally distributed variables. For variables with a nonnormal distribution, we used medians (interquartile ranges [IQRs]) or numbers (percentages).

The distribution was tested for the normality with the Kolmogorov-Smirnov test. Baseline parameters were compared between the subgroups using the Wilcoxon test for variables with nonnormal distribution. Associations between parameters were assessed using the Pearson or Spearmen rank correlation analysis, depending on the parametric or nonparametric distribution of variables. A $P$ value of less than 0.05 was considered significant. Statistical analysis was performed using the Statistica software (version 10.0, Stat Soft, Warsaw, Poland)

RESULTS Study group characteristics A total of 53 patients ( 40 men and 13 women) with severe $C A D$ were included in the study group. All patients had preserved left ventricular ejection fraction with no indications for heart valve surgery and required only a single CABG procedure. Patients characteristics are presented in 
TABLE 1 Clinical characteristics of the study group $(n=53)$

\begin{tabular}{|c|c|}
\hline Parameter & Value \\
\hline Age, $y$, mean (SD) & $64.7(7.4)$ \\
\hline Female / male sex & $13(25) / 40(75)$ \\
\hline Diabetes & $26(49)$ \\
\hline Dyslipidemia & $53(100)$ \\
\hline Total cholesterol, mg/dl, mean (SD) & $152(34)$ \\
\hline LDL cholesterol, mg/dl, mean (SD) & $86(29)$ \\
\hline HDL cholesterol, mg/dl, mean (SD) & $43(11)$ \\
\hline Triglycerides, mg/dl, mean (SD) & $119(50)$ \\
\hline Hypertension & $53(100)$ \\
\hline Smoker or exsmoker & $27(51)$ \\
\hline Number of vessels with CAD, mean (SD) & $2.7(0.5)$ \\
\hline Prior MI & $9(17)$ \\
\hline Body mass index, $\mathrm{kg} / \mathrm{m}^{2}$, mean (SD) & $29.9(4.5)$ \\
\hline Overweight & $28(53)$ \\
\hline Obesity & $21(39)$ \\
\hline Body fat, \%, mean (SD) & $32.2(7.7)$ \\
\hline$W C$, women $>80 \mathrm{~cm}$ or men $>94 \mathrm{~cm}$ & $42(79)$ \\
\hline WC, cm, mean (SD) & $102.4(12.6)$ \\
\hline Metabolic syndrome & $30(56)$ \\
\hline \multicolumn{2}{|l|}{ Cardiovascular pharmacotherapy } \\
\hline Acetylsalicylic acid & $53(100)$ \\
\hline$\beta$-Blocker & $53(100)$ \\
\hline ACEI or ARB & $53(100)$ \\
\hline Statin & $53(100)$ \\
\hline $\mathrm{CCB}$ & $21(39)$ \\
\hline Diuretics & $11(21)$ \\
\hline Insulin & $5(9)$ \\
\hline Oral diabetes medications & $21(40)$ \\
\hline
\end{tabular}

Data are presented as number (percentage) unless otherwise indicated.

Abbreviations: ACEI, angiotensin-converting enzyme inhibitor; ARB, angiotensin II receptor blocker; $C A D$, coronary artery disease; $C C B$, calcium channel blocker; HDL, high-density lipoprotein; LDL, low-density lipoprotein; MI, myocardial infarction; WC, waist circumference

TABLE 1. The expressions of all genes were quantified in PVAT-IMA and compared with other fat depots. In brief, the expression of UCP1 and AGT was higher in PVAT-IMA compared with SF (FIGURE 1A). We found differences in relative expressions of genes between PVAT-IMA and pericardial fat except ITLN1 and ADPIOQ (FIGURE1B). The expression of ITLN1 was higher and the expression of PLTP and ADIPOQ was lower in PVAT-IMA compared with EF (FIGURE $1 C$ ).

The prevalence of cardiovascular risk factors and diseases in our study group was high and similar among patients with severe CAD.
Therefore, we could compare subgroups based on obesity or diabetes mellitus. Patients with obesity had increased expression of GLP1R compared with nonobese individuals (median [IQR], 0.97 [0.17-2.46] vs 0.2 [0.01-0.66]; $P=0.01)$. Diabetes was associated with lower expression of $A G T$ compared with normoglycemic patients (median [IQR], 1.32 [0.17-4.5] vs 4.25 [1.68-8.4]; $P=0.01$ ). There were no other differences in PVAT-IMA between those subgroups (data not shown).

The expression of UCP1 was associated with $P L T P(r=0.35 ; P=0.02)$ and GLP1R $(r=0.3$; $P=0.04)$. Moreover, ACE1 was associated with $A G T$ ( $r=0.7 ; P<0.001)$. Expression of ADIPOQ in pericardial (median [IQR], 1.37 [0.5-4.5]; $P=0.01$ ) and epicardial fat (median [IQR], 0.44 [0.23-2.3]; $P=0.05$ ) was higher compared with PVAT-IMA. Also, in epicardial fat, the expression of PLTP was higher (median [IQR], 1.61 [0.96-3.1]; $P=0.01$ ).

We found no differences in the expressions of the following genes between both fat depots: $A C E 1$ and $A C E 2, G L P 1 R$ and GLP2R, AGT and UCP1.

\section{Perivascular fat in the internal mammary ar-} tery and epicardial fat Associations between genes in both fat depots surrounding the arteries (PVAT-IMA and EF) were assessed. We found higher expression of ADIPOQ (median [IQR], 0.44 [0.23-2.3]; $P=0.05$ ) and PLTP (median [IQR], 1.61 [0.96-3.1]; $P=0.01)$, and lower expression of ITLN1 (median [IQR], 1.01 [0.17-6.1]; $P<0.001)$.

DISCUSSION Omentin is known as an anti-inflammatory and anti-atherogenic adipokine that has potentially beneficial effects on cardiovascular disorders. ${ }^{18}$ It is typically found in the epicardial and omental human fat. ${ }^{19}$ Our study showed increased expression of ITLN1 in PVAT-IMA compared with EF. Nishimura et a $1^{18}$ showed an independent and inverse association between atherosclerosis and plasma omentin levels. Our findings may suggest that the ITLN1 gene expression is higher in PVAT-IMA compared with EF (obtained from the right coronary artery with severe atherosclerosis) and it may be a protective association against atherosclerosis in the IMA. Du et $\mathrm{al}^{20}$ showed similar findings. Moreover, the IMA is known to be the best arterial graft in CABG with excellent life-patency rate. ${ }^{21}$ However, the comprehensive mechanism explaining its exceptional properties is not well explained. On the other hand, quality and quantity (thickness) of epicardial adipose tissue are related with CAD and may help in risk stratification. ${ }^{7}$

We found no differences in the expressions of the following genes between both fat depots: $A C E 1$ and ACE2, GLP1R and GLP2R, and UCP1. 


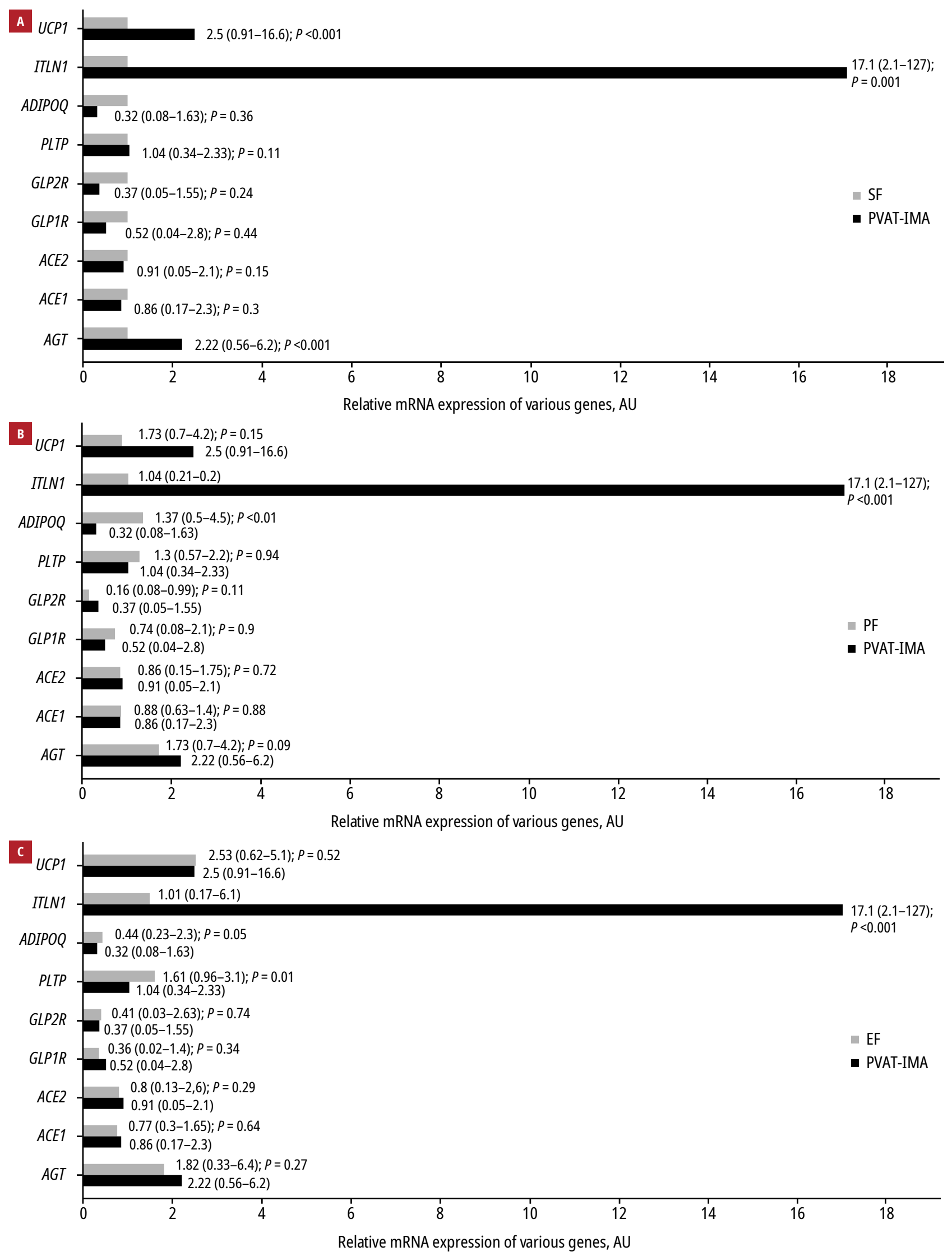

FIGURE 1 Expression of various genes in perivascular adipose tissue samples from the internal mammary artery (PVAT-IMA) $(n=53)$ compared with: A - subcutaneous fat (SF) depot obtained from the sternal region in the same patients; B - pericardial fat (PF) depot obtained from thoracic adipose tissue in the same patients; $\mathbf{C}$ - epicardial fat (EF) depot obtained from the epicardium near the proximal segment of the right coronary artery in the same patients. Statistical analysis using the Wilcoxon test with the medians (interquartile ranges). All panels present the magnitude of change in relation to the subcutaneous fat value. Abbreviations: ADIPOQ, adiponectin; AU, arbitrary unit; $A C E 1$, angiotensin I converting enzyme 1; ACE2, angiotensin I converting enzyme 2; $A G T$, angiotensinogen; GLP1R, glucagon-like peptide 1 receptor; GLP2R, glucagon-like peptide 2 receptor; ITLN1, omentin-1; PLTP, phospholipid transfer protein; UCP1, uncoupling protein 1; others, see TABLE1 
Given the patient characteristics, we found that diabetes was associated with increased UCP1 and AGT in PVAT-IMA. UCP1 is involved in nonshivering thermogenesis and in the pathogenesis of obesity. ${ }^{22}$ The UCP1 gene is located at chromosome 4 and is considered to be involved in the pathogenesis of cardiometabolic diseases. ${ }^{23}$ It has been suggested that brown adipose tissue (BAT) activity, mediated by the UCP1 expression, may contribute to $5 \%$ of the basal metabolic rate,${ }^{24}$ indicative of a regulatory role of BAT in energy balance and body weight. In human adults, the level of UCP1 in BAT decreases with age and it is inversely associated with adiposity. ${ }^{25,26}$ Indeed, individuals with low levels of BAT activity are more susceptible to the abovementioned diseases..$^{27,28}$ UCP1 is regulated both at the gene and the mitochondrial level to ensure a high thermogenic capacity to tissue. ${ }^{29}$ Recent studies showed that activation of UCP1 has become a therapeutic strategy against obesity and diabetes. ${ }^{30}$ It might participate in the pathogenesis of obesity-related metabolic diseases. ${ }^{31}$ In obese patients, UCP1 polymorphism was associated with weight, body fat mass, and risk of type 2 diabetes mellitus. ${ }^{32}$ Our study revealed higher expression of the UCP1 gene in PVAT-IMA compared with SF. Additionally, the UCP1 expression in PVAT-IMA was associated with PLTP and GLP1R.

$A G T$ is expressed in adipose tissue and it might be involved in the development of upper-body obesity. ${ }^{33}$ Recent studies showed that numerous traditional cardiovascular risk factors are associated with the synthesis of $A G T .^{3}$ We found a higher expression of the AGT gene in PVAT-IMA as compared with SF. The increased adipose tissue secretion of AGT is a potential link between insulin resistance and high blood pressure, especially in obese patients. ${ }^{34} \mathrm{We}$ also found that patients with diabetes had a lower expression of AGT compared with normoglycemic patients. Similar results were observed in patients after cardiac surgery. ${ }^{35}$ Overproduction of $A G T$ in adipose tissue induces adipose inflammation, glucose intolerance, and insulin resistance. ${ }^{36}$

Although the physiological role of ADIPOQ has not yet been fully clarified, previous studies showed that an increased $A D I P O Q$ expression in PVAT might contribute to the maintenance of endothelial function in obese patients. ${ }^{13}$ In our study group with the mean (SD) BMI of 29.9 (4.5) kg/m², the expression of ADI$P O Q$ in PVAT-IMA was significantly lower compared with epicardial and pericardial fat depots. There are reports suggesting that low plasma adiponectin concentrations were associated with atherosclerosis ${ }^{37-39}$ and elevated serum adiponectin concentrations were independently associated with a decreased risk for diabetic macroangiopathy. ${ }^{40}$ On the other hand, it was reported that adiponectin shows an inverse association with CAD. ${ }^{41,42}$ Adiponectin levels were found to be decreased in obesity despite antiatherogenic and anti-inflammatory effects. ${ }^{43}$ A recently published meta-analysis suggested that an elevated adiponectin level is an independent predictor of cardiovascular mortality in patients with CAD. ${ }^{44}$ It is a better predictor of coronary endothelial function than other factors such as body mass index, immunoreactive insulin, and TG. ${ }^{45}$ Our study showed that patients with severe CAD had a lower expression of $A D I P O Q$ in PF and EF as well as lower PLTP in EF.

The adenylyl-cyclase pathway is stimulated by GLP1R and in this way insulin is synthesized and released to the blood. ${ }^{46,47}$ Agonists of GLP1R became a target in treating diabetes mellitus. ${ }^{48-50}$ Our patients with obesity had an increased expression of GLP1R in PVAT-IMA compared with nonobese individuals.

This study showed that the expression of ITLN1 in PVAT-IMA was higher compared with other fat depots including surrounding atherosclerotic arteries. The mechanism of IMA relaxation is still unknown and requires more research. The level of ITLN1 expression may play a role in that mechanism. Higher levels of mentioned adipokine expression should be the subject of further studies assessing the cause-and-effect relationship.

Our study has some limitations. It was a cross-sectional study. There was no control group as it is not possible to have a true healthy control with other indications for cardiac surgery procedure.

In conclusion, we found no differences in the expressions of the following genes between both fat depots: AGT, GLP1R and GLP2R, and $U C P 1$, but diabetes was associated with increased UCP1 and AGT expressions in PVAT-IMA.

\section{ARTICLE INFORMATION}

ACKNOWLEDGMENTS The study was supported by a noncommercial research grant from Medical University of Silesia (KNW-1-085/N/5/0; to MH, KNW-1-016/K/8/K; to ZG) and Polish Cardiac Society (Servier 2016).

CONTRIBUTION STATEMENT AK and MH are the guarantors of this work and, as such, had full access to all the data in the study and take responsibility for the integrity of the data and the accuracy of the data analysis.

CONFLICT OF INTEREST None declared.

OPEN ACCESS This is an Open Access article distributed under the terms of the Creative Commons Attribution-Non Commercial-No Derivatives 4.0 International License (CC BY-NC-ND 4.0), allowing third parties to download articles and share them with others, provided the original work is properly cited, not changed in any way, distributed under the same license, and used for noncommercial purposes only. For commercial use, please contact the journal office at kardiologiapolska@ptkardio.pl.

HOW TO CITE Kowalówka A, Machnik G, Deja M, et al. Perivascular adipose tissue from the internal mammary artery in patients with severe coronary artery atherosclerosis. Kardiol Pol. 2020; 78: 1215-1220. doi:10.33963/KP.15645

\section{REFERENCES}

1 Gelber RP, Gaziano JM, Orav EJ, et al. Measures of obesity and cardiovascular risk among men and women. J Am Coll Cardiol. 2008; 52: 605-615.

2 Haberka M, Machnik G, Kowalówka A, et al. Epicardial, paracardial, and perivascular fat quantity, gene expressions, and serum cytokines in patients with coronary artery disease and diabetes. Pol Arch Intern Med. 2019; 129: 738-746. 
3 Niemiec P, Zak I, Wita K. The M235T polymorphism of the AGT gene modifies the risk of coronary artery disease associated with the presence of hypercholesterolemia. Eur J Epidemiol. 2008; 23: 349-354.

4 Antoniades C, Kotanidis CP, Berman DS. State-of-the-art review article. Atherosclerosis affecting fat: what can we learn by imaging perivascular adipose tissue? J Cardiovasc Comput Tomogr. 2019; 13: 288-296.

5 Costa RM, Neves KB, Tostes RC, et al. Perivascular adipose tissue as a relevant fat depot for cardiovascular risk in obesity. Front Physiol. 2018; 9: 253 .

6 Zhang C, Rexrode KM, van Dam RM, et al. Abdominal obesity and the risk of all-cause, cardiovascular, and cancer mortality: sixteen years of follow-up in US women. Circulation. 2008; 117: 1658-1667.

7 Zehir R, Güner A, Hayiroğlu MI, et al. Clinical usefulness of epicardial adipose tissue in patients with high--intermediate pre-test probability for coronary artery disease. Kardiol Pol. 2018; 76: 1002-1008.

8 Fain JN, Madan AK, Hiler ML, et al. Comparison of the release of adipokines by adipose tissue, adipose tissue matrix, and adipocytes from visceral and subcutaneous abdominal adipose tissues of obese humans. Endocrinology. 2004; 145: 2273-2282.

9 Otsuka F, Yahagi K, Sakakura K, et al. Why is the mammary artery so special and what protects it from atherosclerosis? Ann Cardiothorac Surg. 2013; 2: 519-526.

10 Malinowski M, Deja MA, Janusiewicz P, et al. Mechanisms of vasodilatatory effect of perivascular tissue of human internal thoracic artery. J Physiol Pharmacol. 2013; 64: 309-316.

11 Neumann FJ, Sousa-Uva M. 'Ten commandments' for the 2018 ESC/EACTS guidelines on myocardial revascularization. Eur Heart J. 2018; 39: 3759.

12 Voutilainen SM, Jarvinen AA, Verkkala KA, et al. Angiographic 20-year follow-up of 61 consecutive patients with internal thoracic artery grafts. Ann Surg. 1999; 229: 154-158.

13 Cybularz M, Langbein $\mathrm{H}$, Zatschler B, et al. Endothelial function and gene expression in perivascular adipose tissue from internal mammary arteries of obese patients with coronary artery disease. Atheroscler Suppl. 2017; 30: 149-158.

14 Piepoli MF, Hoes AW, Agewall S, et al. 2016 European guidelines on cardiovascular disease prevention in clinical practice. Rev Esp Cardiol (Engl Ed). 2016; 69: 939.

15 Chomczyński P, Sacchi N. Single-step method of RNA isolation by acid guanidinium thiocyanate-phenol-chloroform extraction. Anal Biochem. 1987; 162: 156-159.

16 Wang X, Spandidos A, Wang H, et al. PrimerBank: a PCR primer database for quantitative gene expression analysis, 2012 update. Nucleic Acids Res. 2012; 40: D1144-1149.

17 Livak KJ, Schmittgen TD. Analysis of relative gene expression data using real-time quantitative PCR and the 2(-Delta Delta C(T)) method. Methods. 2001; 25: 402-408

18 Nishimura M, Morioka T, Hayashi M, et al. Plasma omentin levels are inversely associated with atherosclerosis in type 2 diabetes patients with increased plasma adiponectin levels: a cross-sectional study. Cardiovasc Diabetol. 2019; 18: 167.

19 Fain JN, Sacks HS, Buehrer B, et al. Identification of omentin mRNA in human epicardial adipose tissue: comparison to omentin in subcutaneous, internal mammary artery periadventitial and visceral abdominal depots. Int J Obes (Lond). 2008: 32: 810-815.

20 Du Y, Ji Q Cai L, et al. Association between omentin-1 expression in human epicardial adipose tissue and coronary atherosclerosis. Cardiovasc Diabetol. 2016; 15: 90.

21 Malinowski M, Mrozek R, Twardowski R, et al. Left internal mammary artery improves 5-year survival in patients under 40 subjected to surgical revascularization. Heart Surg Forum. 2006; 9: E493-E497; discussion E497-E498.

22 Pan J, Tao C, Cao C, et al. Adipose lipidomics and RNA-Seq analysis revealed the enhanced mitochondrial function in UCP1 knock-in pigs. Biochim Biophys Acta Mol Cell Biol Lipids. 2019; 1864: 1375-1383.

23 Mattson MP. Perspective: does brown fat protect against diseases of aging? Ageing Res Rev. 2010; 9: 69-76.

24 van Marken Lichtenbelt WD, Schrauwen P. Implications of nonshivering thermogenesis for energy balance regulation in humans. Am J Physiol Regul Integr Comp Physiol. 2011; 301: R285-R296.

25 van Marken Lichtenbelt WD, Vanhommerig JW, Smulders NM, et al. Cold-activated brown adipose tissue in healthy men. N Engl J Med. 2009; 360: 1500-1508

26 Saito M, Okamatsu-Ogura Y, Matsushita M, et al. High incidence of metabolically active brown adipose tissue in healthy adult humans: effects of cold exposure and adiposity. Diabetes. 2009; 58: 1526-1531.

27 Flouris $A D$, Piantoni $C$. Links between thermoregulation and aging in endotherms and ectotherms. Temperature (Austin). 2015; 2: 73-85.

28 Carrillo AE, Flouris AD. Caloric restriction and longevity: effects of reduced body temperature. Ageing Res Rev. 2011; 10: 153-162.

29 Porter C. Quantification of UCP1 function in human brown adipose tissue. Adipocyte. 2017; 6: 167-174.

30 Chouchani ET, Kazak L, Spiegelman BM. New advances in adaptive thermogenesis: UCP1 and beyond. Cell MeTAB. 2019; 29: 27-37.

31 Lim J, Park HS, Kim J, et al. Depot-specific UCP1 expression in human white adipose tissue and its association with obesity-related markers. Int J Obes (Lond). 2020; 44: 697-706.
32 Nicoletti CF, de Oliveira AP, Brochado MJ, et al. UCP1 -3826 A>G polymorphism affects weight, fat mass, and risk of type 2 diabetes mellitus in grade III obese patients. Nutrition. 2016; 32: 83-87.

33 van Harmelen V, Elizalde $M$, Ariapart $P$, et al. The association of human adipose angiotensinogen gene expression with abdominal fat distribution in obesity. Int J Obes Relat Metab Disord. 2000; 24: 673-678.

34 Aubert J, Safonova I, Negrel R, et al. Insulin down-regulates angiotensinogen gene expression and angiotensinogen secretion in cultured adipose cells. Biochem Biophys Res Commun. 1998; 250: 77-82.

35 Roubicek T, Dolinkova M, Blaha J, et al. Increased angiotensinogen production in epicardial adipose tissue during cardiac surgery: possible role in a postoperative insulin resistance. Physiol Res. 2008; 57: 911-917.

36 Kalupahana NS, Massiera F, Quignard-Boulange A, et al. Overproduction of angiotensinogen from adipose tissue induces adipose inflammation, glucose intolerance, and insulin resistance. Obesity (Silver Spring). 2012; 20: 48-56.

37 Dunajska K, Milewicz A, Jędrzejuk D, et al. Plasma adiponectin concentration in relation to severity of coronary atherosclerosis and cardiovascular risk factors in middle-aged men. Endocrine. 2004; 25: 215-221.

38 Souza RA, Alves CMR, de Oliveira CSV, et al. Circulating levels of adiponectin and extent of coronary artery disease in patients undergoing elective coronary angiography. BrazJ Med Biol Res. 2017; 51: e6738.

39 Diah $\mathrm{M}$, Lelo $\mathrm{A}$, Lindarto $\mathrm{D}$, et al. Plasma concentrations of adiponectin in patients with coronary artery disease and coronary slow flow. Acta Med Indones. 2019; 51: 290-295.

40 Chen T, Tu M, Huang L, et al. Association of serum adiponectin with intima media thickness of dorsalis pedis artery and macroangiopathy in type 2 diabetes. Diabetes Res. 2020; 2020: 4739271.

41 Persson J, Folkersen L, Ekstrand J, et al. High plasma adiponectin concentration is associated with all-cause mortality in patients with carotid atherosclerosis. Atherosclerosis. 2012; 225: 491-496.

42 Au Yeung SL, Schooling CM. Adiponectin and coronary artery disease risk: a bi-directional Mendelian randomization study. Int J Cardiol. 2018; 268: 222-226.

43 Umeda LM, Pereira AZ, Carneiro G, et al. Postprandial adiponectin levels are associated with improvements in postprandial triglycerides after Roux-en-Y gastric bypass in type 2 diabetic patients. Metab Syndr Relat Disord. 2013; 11: 343-348. 44 Yang L, Li B, Zhao Y, et al. Prognostic value of adiponectin level in patients with coronary artery disease: a systematic review and meta-analysis. Lipids Health Dis. 2019; 18: 227.

450 ui $\mathrm{H}$, Hamasaki $\mathrm{S}$, Ishida $\mathrm{S}$, et al. Adiponectin is a better predictor of endothelial function of the coronary artery than HOMA-R, body mass index, immunoreactive insulin, or triglycerides. Int J Cardiol. 2008; 126: 53-61.

46 Widmann C, Dolci W, Thorens B. Heterologous desensitization of the glucagon-like peptide-1 receptor by phorbol esters requires phosphorylation of the cytoplasmic tail at four different sites. J Biol Chem. 1996; 271: 19957-19963. 47 Lockie SH, Heppner KM, Chaudhary N, et al. Direct control of brown adipose tissue thermogenesis by central nervous system glucagon-like peptide-1 receptor signaling. Diabetes. 2012; 61: 2753-2762.

48 Holscher C. Drugs developed for treatment of diabetes show protective effects in Alzheimer's and Parkinson's diseases. Sheng Li Xue Bao. 2014; 66: 497-510.

49 Ban K, Noyan-Ashraf MH, Hoefer J, et al. Cardioprotective and vasodilatory actions of glucagon-like peptide 1 receptor are mediated through both glucagon-like peptide 1 receptor-dependent and -independent pathways. Circulation. 2008; 117: $2340-2350$.

50 Vilsboll T, Christensen M, Junker AE, et al. Effects of glucagon-like peptide-1 receptor agonists on weight loss: systematic review and meta-analyses of randomised controlled trials. BM]. 2012; 344: d7771. 